\section{Inviting Young Chemists to the 43rd IUPAC Congress in Puerto Rico}

\section{he 2011 IUPAC Congress will take place 30 July-7 August in San Juan, Puerto Rico's new, state-of-the-art Convention Center. The theme of the Congress is "Chemistry Bridging Innovation Among the Americas and the World." The event will be a major cornerstone of the 2011 International Year of Chemistry and a unique opportunity to celebrate the achievements of chemistry and its contributions to the well-being of humankind.}

To encourage young chemists to participate in the 43rd IUPAC Congress, the organizers have established two different Young Chemists Award programs, both offering travel assistance to Puerto Rico.

The two award programs are as follows:

- Program A is especially targeted at young scientists from developing and economically disadvantaged countries.

- Program B is open to chemists from any country.

\section{Young Observers at the IUPAC General Assembly}

Concurrent with the Young Chemists initiative, IUPAC and individual National Adhering Organizations (NAOs) are again offering a Young Observer program to provide young scientists with the opportunity to participate in sessions of the IUPAC General Assembly. Sessions of the General Assembly are generally reserved to IUPAC members of specific divisions and committees, but Young Observers can participate in these meetings-a unique opportunity to learn about IUPAC activities, establish international collaborations, and gain knowledge of global research activities.

IUPAC Young Observers will be invited from the pool of Young Chemists awards granted by the IUPAC Congress. Other NAOs, such as the USA, may have their own selection process. Those who are interested should inquire with the NAO from their country: www.iupac.org/nao.

iii- www.iupac.org/web/nt/2010-11-05_43_Congress

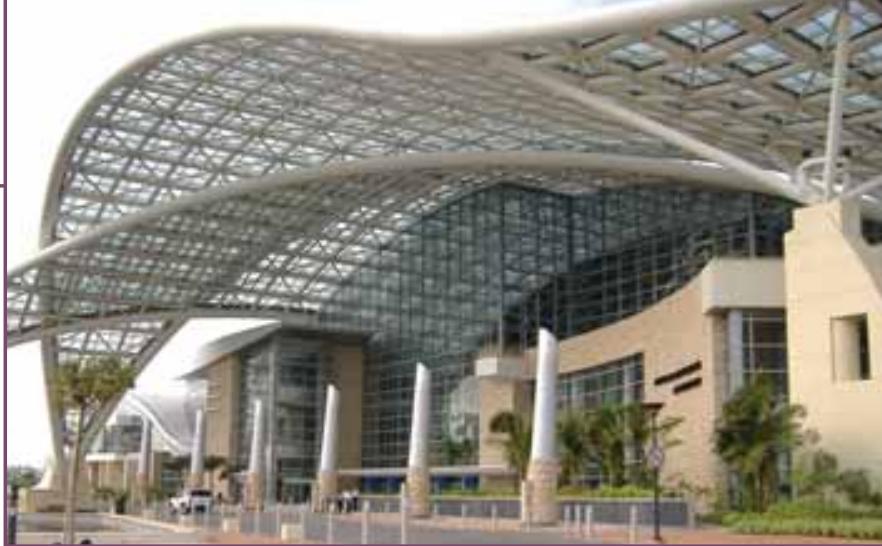

The Puerto Rico Convention Center, site of the 2011 IUPAC Congress.

Awards of up to USD 1500 will be made available to qualified candidates as a contribution to the costs of their travel to attend the Congress and to meet Congress registration fees.

Applications are welcomed from candidates under age 40 who received their Ph.D. less than five years ago. Scientists from academia, government, or industry may submit applications directly to the address below. Successful applicants will be expected to submit an oral or poster presentation abstract to be presented at the Congress. Such abstracts will be subject to adjudication as will all other submissions for presentation at the meeting.

Applicants are asked to return the application form, and complete it with the following information:

- letter of application

- brief CV

- confirmation of their current status and affiliation;

- publication list (5-10 top)

- the title of their abstract submission to the IUPAC 2011 Congress

- letter of support from the appropriate department head, dean, or laboratory supervisor

- an estimate of the applicant's economy airfare to and from the Congress

Applicants are not required to be a member or affiliate of IUPAC to be eligible for a Young Chemists Award. The deadline for receipt of applications is 28 February 2011. Applications should be sent to<info@ iupac2011.org> or <restoe@iupac2011.org> with IUPAC Young Chemists Award in the subject line. Visit the Congress website for more info.

Cinil www.iupac2011.org 